\title{
ANÁLISE DO DISCURSO DO SUJEITO COLETIVO NA EVASÃO NO ENSINO SUPERIOR DE TECNOLOGIA
}

\author{
Paulo Roberto da Silva ${ }^{1}$; Lucia Maria Gomes Corrêa Ferri ${ }^{2}$; Ivone Tambelli Schimidt ${ }^{2}$ \\ ${ }^{1}$ Docente da Faculdade de Tecnologia de Presidente Prudente - FATEC. ${ }^{2}$ Docentes do programa de Mestrado em \\ Educação da UNOESTE. E-mail: paulo.vj@terra.com.br
}

\section{RESUMO}

Com a ampliação da oferta de vagas nas Instituições de Educação Superior, em especial as de formação tecnológica, houve crescimento significativamente maior dos indicadores de evasão. Trata-se de pesquisa realizada na forma de estudo de caso em instituição pública de ensino superior de tecnologia, instalada no município de Presidente Prudente, de natureza qualiquantitativo. Os procedimentos metodológicos utilizados: pesquisa documental, com a análise dos prontuários de evadidos, planos dos cursos e da legislação sobre a Educação Profissional no Brasil, seguido da realização de entrevista com gestores (direção e coordenação), corpo docente e alunos evadidos. Através do discurso do sujeito coletivo (DSC) preconizado por Lefevre e Lefevre, com intuito de conhecer as causas acadêmicas da evasão dos alunos dos cursos superiores de tecnologia. Tal entendimento subsidiará os gestores da unidade de ensino, rediscutir seus procedimentos pedagógicos e norteará na adoção de ações e políticas que contribuam para minimizar os indicadores de evasão.

Palavras-chave: Ensino profissional. Tecnólogos - Formação. Evasão escolar.

\section{INTRODUÇÃO E OBJETIVO}

Diante de um cenário econômico competitivo, cujo domínio da tecnologia e habilidades e competências são determinantes para o sucesso, concluir um curso superior torna-se uma conquista ímpar, porém, representa cada dia mais, o mínimo necessário em um mercado de trabalho cada vez mais competitivo. As exigências de escolaridade são cada vez maiores e se traduzem em oportunidade de melhor emprego e remuneração.

A Educação tão necessária, apesar da expansão do número de vagas, tem se contraposto ao número de formandos. O fenômeno da evasão é considerado um dos maiores problemas enfrentados pelas Instituições de Ensino Superior, sejam públicas ou privadas.

Veloso (2000, p, 14), assegura que:

A evasão de estudantes é um fenômeno complexo, comum às instituições universitárias no mundo contemporâneo. Nos últimos anos, esse tema tem sido objeto de alguns estudos e análises, especialmente nos países do primeiro mundo, e têm demonstrado não só a universalidade do fenômeno como a relativa homogeneidade de seu comportamento em determinadas áreas do saber, apesar das diferenças entre as instituições de ensino e das peculiaridades sócio-econômico culturais de cada país. 
Destaca-se os reflexos sociais negativos, pois, para o acadêmico e muitas vezes às famílias a evasão sepulta a possibilidade da realização de um sonho, com a consequente sensação de perda, além do desperdício de tempo e de dinheiro. Também, os avanços tecnológicos e econômicos são afetados, pela falta de qualificação causada pela evasão. Vivemos em uma sociedade cuja formação e desenvolvimento dos recursos intelectuais demonstram-se cada dia mais imprescindíveis às nações.

A evasão é um problema que afeta o resultado dos sistemas educacionais, com consequentes desperdícios acadêmicos e econômicos, porém, mais significativos, indubitavelmente, são os problemas sociais que pode acarretar.

Todo o aparato de recursos disponibilizados para que os cursos ocorram, é estimado com base na demanda e, a priori, espera-se que contribua para que todos concluam o respectivo curso.

Segundo Manfredi (2002), as rápidas transformações no mundo do trabalho, o avanço tecnológico que configura a sociedade virtual, a evolução e o dinamismo dos meios de informação e comunicação incidem fortemente na escola e aumentam os desafios para torná-la uma conquista efetiva e realmente democrática.

A democratização do ensino passa necessariamente pela instituição de ensino e pelos professores, portanto, é imperativo compreender o processo de evasão e sua relação com a metodologia didático-pedagógica.

Destaca-se a relevância do tema, além de instrumentalizar os gestores na toma de decisões, também instrumentaliza a adoção de políticas públicas que estimulem a permanência e a conclusão dos cursos, com reflexos sociais expressivos, em razão da inserção do formando no mercado de trabalho, hoje, muito carente de qualificação profissional.

Compreender os fatores acadêmicos relacionados ao processo da evasão de estudantes no ensino superior de tecnologia possibilita:

- Analisar as políticas de investimento e expansão das vagas no ensino superior tecnológico;

- Fornecer subsídios à direção da unidade na gestão de ações e políticas que contribuam para minimizar os indicadores de evasão;

- Analisar fatores acadêmicos que contribuem para a manutenção dos estudantes nos cursos;

- Analisar fatores acadêmicos que contribuem para o aumento dos índices de evasão escolar. 


\section{METODOLOGIA}

A pesquisa tem um enfoque qualiquantitativo, com intuito de poder conhecer os motivos pelos quais ocorre a evasão no ensino superior de tecnologia. Para tanto, utilizamos o estudo de caso, com intuito de permitir observar detalhadamente o contexto, ou indivíduo, de uma única fonte documental ou de um acontecimento específico (LESSARD-HÉBERT, GOYETTE, BOUTIN, 2008).

Para analisar os motivos pelos quais ocorre o ingresso e as causas de evasão dos estudantes de ensino superior de tecnologia, realizou-se incialmente uma pesquisa documental.

Após os levantamentos nos prontuários, ocorram entrevistas individuais semiestruturadas e, para a análise utilizou-se a Metodologia do Discurso do Sujeito Coletivo - DSC, desenvolvido por Lefevre e Lefevre (2005, p.25):

O DSC consiste, então, numa forma não-matemática nem metalinguística de representar (e de produzir), de modo rigoroso, o pensamento de uma coletividade, o que se faz mediante uma série de operações sobre os depoimentos, que culmina em discursos-síntese que reúnem respostas de diferentes indivíduos, com conteúdos discursivos de sentido semelhante.

\section{RESULTADOS}

No Censo do Ensino Superior 2010, divulgado pelo Instituto Nacional de Estudos e Pesquisas Educacionais Anísio Teixeira (INEP) em outubro de 2012, é indicado que o número de matrículas nos cursos de graduação aumentou em 7,1\% de 2009 a 2010 e no período entre 2001 a 2010 aumentou $110,1 \%$.

Também, o Censo 2010 apontou a trajetória de exponencial de expansão das matrículas nos cursos tecnológicos, que em 2001 era de 69.797 e atingiu em 2010 um total de 781.609 matrículas.

Quanto a oferta de cursos superiores de tecnologia no Brasil, Moll et al. (2010, p. 175) e conforme dados do Censo da Educação Superior do INEP/MEC (BRASIL, 2007), apontam que houve um expressivo crescimento da ordem de $1200 \%$ entre 1997 e 2007, sendo mais significativo o crescimento no período entre 2004 e 2007, em percentual superior ao crescimento anual dos demais cursos superiores (bacharelado ou licenciatura).

Apesar de todas as justificativas plausíveis para explicar o baixo desempenho de produtividade das instituições, mais significativo e relevante é reconhecer o papel social das instituições de ensino, em especial as de Educação Profissional, tornando-se inquestionável a 
necessária busca por alternativas que possibilitem a manutenção das vagas e a consequente conclusão do curso iniciado aos alunos.

Conforme afirmaram Kotler e Fox (1994), é imprescindível a manutenção de alunos para as instituições de ensino, pois os alunos constituem a razão da existência dessas instituições. Se não houver alunos seguramente as escolas fechariam suas portas. Tão importante quanto a efetivação de novas matrículas de alunos é garantir àqueles que estão estudando sua rematrícula.

Tabela 1. Matrículas / Concluintes / Vagas por categoria de graduação 2011

\begin{tabular}{lr|r|r|r|r}
\hline \multirow{2}{*}{ Matrículas / Concluintes / Vagas } & \multicolumn{5}{|c}{ Total Geral } \\
\cline { 2 - 6 } & \multicolumn{1}{|c|}{ Total } & $\begin{array}{c}\text { Bacha } \\
\text { relado }\end{array}$ & $\begin{array}{c}\text { Licenciatur } \\
\text { a }\end{array}$ & Tecnólogo & $\begin{array}{c}\text { Não } \\
\text { Aplicável }\end{array}$ \\
\hline Matrículas & 6.739 .689 & 4.495 .831 & 1.356 .329 & 870.534 & 16.995 \\
Pública & 1.773 .315 & 1.039 .539 & 588.329 & 128.533 & 16.914 \\
Federal & 1.032 .936 & 649.318 & 309.185 & 68.184 & 6.249 \\
Estadual & 619.354 & 298.474 & 254.094 & 56.121 & 10.665 \\
Municipal & 121.025 & 91.747 & 25.050 & 4.228 & - \\
Privada & 4.966 .374 & 3.456 .292 & 768.000 & 742.001 & 81 \\
\hline Concluintes & 1.016 .713 & 607.971 & 238.107 & 170.635 & - \\
Pública & 218.365 & 124.312 & 75.021 & 19.032 & - \\
Federal & 111.157 & 68.963 & 30.699 & 11.495 & - \\
Estadual & 87.886 & 42.384 & 39.086 & 6.416 & - \\
Municipal & 19.322 & 12.965 & 5.236 & 1.121 & - \\
Privada & 798.348 & 483.659 & 163.086 & 151.603 & - \\
\hline Vagas Oferecidas & 4.453 .431 & 2.348 .664 & 972.675 & 1.120 .180 & 11.912 \\
Pública & 531.489 & 279.955 & 187.166 & 52.576 & 11.792 \\
Federal & 300.808 & 173.907 & 94.926 & 24.476 & 7.499 \\
Estadual & 163.510 & 63.242 & 72.990 & 22.985 & 4.293 \\
Municipal & 67.171 & 42.806 & 19.250 & 5.115 & - \\
Privada & 3.921 .942 & 2.068 .709 & 785.509 & 1.067 .604 & 120 \\
\hline Fonte: MEC/INEP/DEED & & & & & \\
\end{tabular}

Na Tabela 1 abaixo, observamos os dados divulgados na Sinopse da Educação Superior 2011, onde podemos realizar um comparativo entre o número de matrículas, concluintes e vagas, evidenciando a expansão de vagas e da demanda, mas também do baixo número de concluintes, evidenciando a evasão. Há uma enorme disparidade entre o número de vagas, matrículas e concluintes: das 1.120 .180 vagas oferecidas, 870.534 consolidaram-se como matrículas e apenas 170.635 concluíram os cursos iniciados. 
No Brasil, a "educação tecnológica" refere-se a formação de nível superior de curta duração, entre dois ou três anos, dependendo do curso, voltada especificamente para a capacitação para o efetivo exercício profissional, já a "educação técnica" se refere à formação profissional de nível médio.

As novas exigências e requisitos do mercado de trabalho, à primeira vista estariam consonantes e fortemente alinhados com a expansão da educação profissional. A ampliação da sociedade do conhecimento em prol do desenvolvimento se dá através da expansão do ensino superior, tornando-se necessário o aumento da competência técnica, que se dá através da educação profissional, requerida e necessária ao desempenho de tarefas complexas, porém cada vez mais especializadas em setores da indústria e dos serviços.

\section{DISCUSSÃO}

Fundamentado nas entrevistas realizadas, junto à instituição pesquisada, podemos concluir que, para os gestores, a evasão se dá em alguns casos em razão do aluno desconhecer o perfil de formação do curso e apresentarem dificuldades em acompanhar o desenvolvimento das aulas, tendo em vista o baixo grau de conhecimento trazidos do ensino fundamental. Há concordância unânime que o fator principal é a necessidade de trabalho. $O$ aluno ao deparar-se com dificuldade em conciliar trabalho e estudo, para que possa ajudar a família e a si próprio opta por abandonar o curso.

A direção e coordenação estão atentas às necessidades dos docentes, visto que o acompanhamento das atividades são sistematicamente registradas, proporcionando-lhes momento para a realização do planejamento pedagógico e proporcionando condições para a realização de plantões didáticos e monitores (alunos) para auxílio em sanar eventuais dúvidas. Tais ações são necessárias, em razão do grau de defasagem dos estudos dos alunos ingressantes, decorrentes da qualidade de ensino proporcionada no ensino fundamental.

As ações mencionadas anteriormente, não são capazes de sanar todas as dificuldades, porém, são significativas em auxiliar e amenizar a evasão e, acima de tudo, contribuir para a oportunidade de boa formação profissional e consequente possiblidade de novas conquistas de emprego e renda.

Os docentes indicaram que algumas ações poderiam proporcionar reflexos de melhorias nos processos de ensino e aprendizagem, impactando em redução da evasão: agir com maior flexibilidade e demonstrando a aplicabilidade dos conteúdos desenvolvidos, além de trabalhar 
Colloquium Humanarum, vol. 10, n. Especial, Jul-Dez, 2013, p. 567-575. ISSN: 1809-8207. DOI: 10.5747/ch.2013.v10.nesp.000498

com maior comprometimento, demonstrando possuir conhecimentos suficientes ao desenvolvimento das aulas, em respeito aos alunos e pelo zelo da qualidade do ensino.

Os alunos apresentam dificuldades no desenvolvimento de algumas atividades, mas, indubitavelmente o maior problema apresentado refere-se em conciliar o trabalho com os estudos. Poucos se informaram a respeito do plano de curso e perfil de formação que lhe é proporcionado, porém, demonstram não saber distinguir entre cursos de tecnologia dos cursos de licenciatura e de bacharelado.

\section{CONCLUSÃO}

Sob a égide de atender as demandas do mercado de trabalho e desenvolvimento econômico, desconsidera-se as dificuldades institucionais e, sobretudo do aluno que se evade ao deparar-se com dificuldades cognitivas e relacionadas a conciliar trabalho e estudo.

Tal fato denota um desalinhamento das políticas atuais, voltadas para a ampliação das vagas, sem, contudo, acompanhar e propiciar condições aos educandos para a conclusão do curso iniciado.

Mediante as respostas obtidas na pesquisa, possibilitou-nos inferir que a instituição pesquisada ampliou a oferta de vagas e, embora em seus currículos estejam voltados a contemplar as necessidades do mercado de trabalho, há aspectos relevantes que carecem de maior atenção como proporcionar condições adequadas ao desenvolvimento das atividades dos cursos.

Nota-se que a velocidade com que ocorre a ampliação das vagas não é acompanhada pelos investimentos necessários em estrutura física, com ambientes propícios e adequados aos cursos oferecidos; de equipamentos tecnologicamente adequados e atualizados e em quantidade suficientes às práticas pedagógicas; e de apoio ao desenvolvimento das atividades docentes e discentes, como biblioteca que que contem plenamente com acervos de livros, periódicos e vídeos dentre outros, atualizados e alinhados com o perfil de formação de cada curso.

Em diversos momentos da pesquisa com gestores, docentes e evadidos, emergiu a palavra "motivar". Longe de querer argumentar sobre o tema, depreende-nos considerar que, apesar da complexidade a motivação é algo inerente ao ser humano e flui do interior de cada indivíduo, portanto, não há como um indivíduo diretamente motivar outro. Ocorre, porém, que alguns fatores podem contribuir para um sentimento de acolhimento, de bom convívio e bom ambiente de trabalho, de realização pessoal e profissional, dentre outros fatores que, por consequência, podem contribuir para que ocorra um bem estar e possa contribuir para que os atores da unidade 
escolar sintam-se motivados. Nota-se que, em termos gerais, há um bom relacionamento e respeito, entre todos os que frequentam a faculdade, a serviço ou estudo.

Quanto à motivação discente refere-se, além de ambiente adequado ao aprendizado e professores bem preparados para a condução dos processos de ensino e aprendizagem e disporem de tempo para conciliarem trabalho e estudo, vislumbrarem conhecer previamente o perfil de formação que terão e mais, a possibilidade de exercício da atividade a qual estão estudando.

Deparamo-nos com instituições tanto públicas como privadas ampliando a oferta de vagas, sem a devida preocupação ou discussão e, principalmente, completamente inexistente a implementação de políticas afirmativas e inclusivas, que possibilitem eliminar o problema da evasão escolar e promover o resgate da cidadania perdida.

É patente a frustração do aluno que, ao ingressar em um curso superior cria sonhos e potencializa seus ideais. Ocorre um sentimento de perda, como de fato representa a não conclusão do curso iniciado. Muitas vezes a oportunidade para a realização pessoal e profissional que deixará de ocorrer, além da questão financeira tanto dos alunos evadidos que não poderão contemplar plenamente os recursos investidos, inclusive de tempo, pela interrupção do curso, mas também, às instituições que investem e criam estruturas para atender determinada demanda que decai decorrente da evasão.

\section{REFERÊNCIAS}

INEP - INSTITUTO NACIONAL DE ESTUDOS E PESQUISAS EDUCACIONAIS ANÍSIO TEIXEIRA. Censo da Educação Superior 2007: resumo técnico. Brasília: Inep, 2009. Disponível em: <http://download.inep.gov.br/download/superior/censo/2007/Resumo_tecnico_2007.pdf>. Acesso em: 07 jan. 2012.

. Censo da Educação Superior 2010: resumo técnico. Brasília: Inep, 2012. Disponível em: <http://download.inep.gov.br/educacao_superior/censo_superior/resumo_tecnico/resumo_tecni co_censo_educacao_superior_2010.pdf>. Acesso em: 05 maio 2012.

Disponível em:

Censo da Educação Superior 2011: resumo técnico. Brasília: Inep, 2013.

<http://download.inep.gov.br/educacao_superior/censo_superior/resumo_tecnico/resumo_tecni co_censo_educacao_superior_2011.pdf>. Acesso em: 21 abr. 2013.

KOTLER, P.; FOX, K. F. A. Marketing estratégico para instituições educacionais. São Paulo: Atlas, 1994.

LEFEVRE, F.; LEFEVRE, A. M. C. Depoimentos e discursos: uma proposta de análise em pesquisa social. Brasília: LiberLivro, 2005. 
LESSARD-HÉBERT, M.; GOYETTE, G.; BOUTIN, G. Investigação qualitativa: fundamentos e práticas. 3. ed. Lisboa: Instituto Piaget, 2008.

MANFREDI, S. M. Educação profissional no Brasil. São Paulo: Cortez, 2002.

MOLL, J. et al. Educação profissional e tecnológica no Brasil contemporâneo: desafios, tensões e possibilidades. Porto Alegre: Artmed, 2010.

VELOSO, T. C. M. A. A evasão nos cursos de graduação da Universidade Federal de Mato Grosso, campus universitário de Cuiabá 1985/2 a 1995/2 - um processo de Exclusão. 2000. Dissertação (Mestrado em Educação) - Universidade Federal do Mato Grosso, Cuiabá, MT. 